\title{
Participation in the convention on migratory species: A biogeographic assessment
}

\author{
Christopher Michael Hensz, Jorge Soberón
}

Received: 1 May 2017/Revised: 23 August 2017/Accepted: 1 February 2018/Published online: 24 February 2018

\begin{abstract}
The Convention on the Conservation of Migratory Species of Wild Animals (CMS) is a Multilateral Environmental Agreement (MEA) focused on species that regularly travel across international borders. Despite covering an important group of species, CMS is under-utilized compared to other conservation-focused MEAs. CMS suffers from a lack of participation across North America and most of Asia. Our goal is to illustrate differences in species richness and average range-size across signatory and nonsignatory nation-states using range-diversity plots. We also show differences in the cost of CMS membership relative to species patterns to highlight which countries may be discouraged from becoming CMS signatories. Despite containing many CMS species, large economies such as the United States, Russia, and China are not members of the convention. To facilitate migratory species conservation into the future, CMS should seek to fill gaps in participation, potentially directing recruitment efforts toward nonsignatory states that would receive the largest benefit at the lowest relative cost.
\end{abstract}

Keywords Conservation policy · Convention on Migratory Species .

Multilateral Environmental Agreement · Spatial ecology

\section{INTRODUCTION}

Multilateral Environmental Agreements (MEAs) are legally binding instruments between two or more nation-states that address environmental issues (Dodds et al. 2007). Approximately, 700 international agreements can be identified as MEAs (Kim 2013). According to Koester (2002), the most important MEAs concerning biodiversity conservation are the Convention on Biological Diversity (CBD 1992), the Convention on International Trade in Endangered Species of Fauna and Flora (CITES 1973), the Convention on Wetlands of International Importance (RAMSAR 1971), the Convention Concerning the Protection of the World Cultural and Natural Heritage (WHC 1972), and the Convention on the Conservation of Migratory Species of Wild Animals (CMS 1979). Of these, the CBD is regarded as the most politically salient, and CITES the most operative in administrative regulation $(\mathrm{Gu}-$ ruswamy 1999). Despite the ecological importance of transboundary species movements (Clobert et al. 2012), CMS is the only MEA focused broadly on migratory species across taxonomic divisions. Unlike CITES, CMS lacks stringent participation requirements for party states. Instead, CMS operates by facilitating the creation of smaller cooperative agreements (Seelarbokus 2014), including as many as 106 "action plans" across seven major conservation agreements and 19 nonbinding Memoranda of Understanding (MoUs). These agreements under CMS administration have helped to stabilize populations of migratory species including Wadden Sea seals (Phoca vitulina vitulina and Helichoerus grypus) and the Bukhara deer (Cervus elaphus bactrianus) despite being nonbinding (Baldwin 2011). Since its initial signing in 1979, CMS membership increased from 29 signatories to 126 party states by 2017 (Guruswamy and Doran 2007; Birnie et al. 2009).

CMS defines migratory species as those "whose members cyclically and predictably cross one or more national jurisdictional boundaries" (CMS 1979). CMS also covers several species that cross international borders but are nonmigratory such as marine otters (Lontra felina) and mountain gorillas (Gorilla gorilla). CMS lists migratory species in two appendices as agreed upon by party states: 
Appendix I includes endangered species restricted from taking (harvesting, hunting, etc.), Appendix II lists species with unfavorable conservation status that may benefit from international cooperation, but are not restricted from taking. Several levels of biological organization are listed in each appendix (genera, species, subspecies, and populations) and these groups may be included in either or both appendices (CMS Appendix I and II, updated October 2017).

Becoming a party to CMS represents a large investment of expertise and time. CMS signatories agree to (i) undertake active conservation of migratory species under the first appendix of the agreement, (ii) form additional international agreements to conserve species in the second appendix, (iii) participate in the tri-annual Conference of the Parties, and (iv) financially support the CMS secretariat (CMS 1979). A significant obstacle to encouraging large, economically powerful states to joining the convention is the cost of being a signatory. Similar to the General Assembly of the United Nations, the cost of participation in CMS is weighted by the GDP of signatory states (UNEP/ CMS Res 12.2).

In this contribution, we aim to describe CMS from a biogeographic perspective to identify which countries may be most amenable to becoming signatories. We analyze the geographic structure of the species covered under CMS Appendix I and II using range-diversity plots (Arita et al. 2008) and relate the results of these plots to United Nations (UN) economic indices as a measure of participation cost. We aim to provide international policymakers the tools to evaluate the potential conservation benefits of joining CMS.

\section{MATERIALS AND METHODS}

We obtained the full record of 1115 CMS species through Species+, a database of CMS and CITES species (http:// speciesplus.net; accessed March 2nd 2017). We aggregated the data to include a single record for each species, consolidating all species with multiple listed subpopulations and species under both CMS appendices. Sixty-two species included no range data and were excluded from this analysis. Species+ database lists the countries where each species is found, but has no data for geographic range size by country, limiting analysis to the country scale.

The Holy See and South Sudan were excluded from analysis for poor data quality: The Holy See contains zero records, and South Sudan could not be completely distinguished from Sudan in the database. Consequently, the maps we present depict a single united Sudan, reflecting the resolution of species data rather than political reality. Greenland was excluded from analysis as it has no established relationship with CMS and is independent of Denmark in its conservation decisions. The Cook Islands and Niue, despite being technically in association with New Zealand, have signed CMS independently and are thus treated as independent for this study (http://www.cms. int/en/parties-range-states; accessed March 2, 2017). For all other countries, we aggregated species data to the level of sovereign states, including all territories under each country (including American Samoa for the United States, French Guiana for France, etc.).

We used two sources of data to determine the economic cost of being a party to CMS. For most signatory states, the financial contribution of each country from $2018-2020$ is presented in reports from the 12th Conference of Parties in 2017 (COP12; UNEP/CMS/Resolution 12.2, pp. 5-8). Parties to CMS contribute funding proportional to the size of their respective economies, measured in gross domestic product (GDP). To estimate the cost for a non-party to become a member of CMS, we added proportional 2018 GDP estimates for individual non-party states obtained from the United Nations General Assembly (UNGA Res A/70/416/Add.1, pp. 3-8) to the CMS document and calculated cost based on the new proportional GDP. We obtained the signatory status of each country and designation of sovereign territories through the CMS web page (http://www.cms.int/en/parties-range-states; accessed March 2nd 2017).

We characterized species patterns for each country using richness-diversity diagrams, a biogeographic exploratory tool (Arita et al. 2008; Soberón and Ceballos 2011) grouping the plots by (i) $k$-means clustering (MacQueen 1967) and (ii) CMS geographic region. $k$-means clustering of the range-diversity plots divides countries into groups that have similar properties based upon species-level patterns. Alternatively, grouping by the six CMS geographic regions (North America, Europe, Asia, Australia and Oceania, Africa, and South America, and the Caribbean) indicates whether or not geographic proximity plays a dominant role in CMS species patterns. Richness-diversity diagrams use the presence-absence data to describe species compositions of each recorded location in a dataset. From these diagrams, it is possible to extract biodiversity indices including alpha and beta diversities (Soberón and Cavner 2015). The horizontal axis shows the proportional mean range size, also called the dispersal field, of the species in each location (Graves and Rahbek 2005). Proportional mean range size (referred from here on as simply 'rangesize'), indicates how cosmopolitan species are for each location. For example, if a country has a relatively large range-size value (e.g., $>0.75$ ), species within that country occur in at least $75 \%$ of countries on average; further, a range-size value of 1 means that all species in that country are represented globally. The minimum possible range-size 
value, $1 / n$, (where $n$ is the number of sites) indicates that all species present in a country are endemic and thus nonmigratory. Calculations were performed in $\mathrm{R}$ ( $\mathrm{R}$ Core Team 2017), and the resulting maps were created in ArcGIS (ESRI 2011).

\section{RESULTS AND DISCUSSION}

$\mathrm{K}$-means clustering analyses identified four distinct groups of countries (referred to as groups A, B, C, and D; Fig. 1). Group A includes 32 countries with the largest number of CMS species, the five with the most species being France, China, Great Britain, Russia, and India (Table 1). Both Great Britain and France are sovereign over territories in multiple hemispheres (including sub-Antarctic island territories), inflating the overall number of species observed for those countries. India, Russia, and China also contain a large number of CMS species ( $>350$ ), perhaps due to large geographic extent. Despite participating in at least one
MoU administered by the CMS secretariat and being the second and fourth largest hosts of CMS species, respectively, neither China nor Russia is currently members of CMS. Nonsignatory countries in group A may be more amenable to joining CMS signatories as they already contain many species listed under CMS.

Group B comprises 83 countries across Europe, Africa, and Central Asia forming the center mass of the richnessdiversity diagram. Group B contains the largest proportion of signatory states of any group (79.5\%) and contains countries with moderate species richness and range-size values. Countries in group B on average contain fewer CMS species than countries in group $\mathrm{A}$, but both groups contain species with moderate range-sizes, found in approximately $30-40 \%$ of countries worldwide (Table 1).

Group C encompasses 34 countries across North America, South America, Southeast Asia, Australia, and Oceania with CMS species that are more restricted in range-size. These species occur in relatively fewer countries $(<35 \%)$, less than $75 \%$ of all other CMS species.

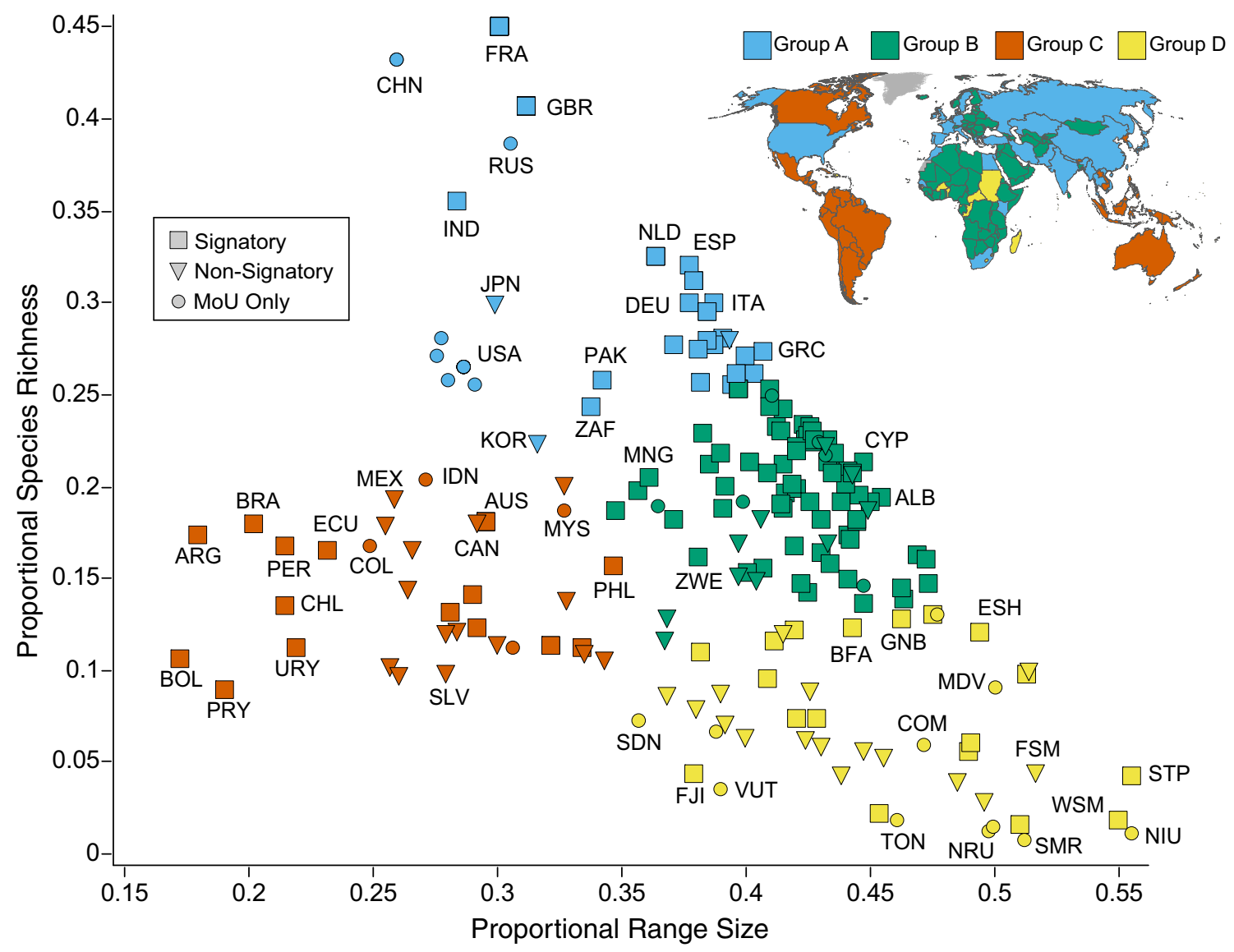

Fig. 1 Richness-diversity diagram and map of countries grouped by $k$-means clustering. Diagram depicts the relationship between the number of CMS species in a country and the average range-size of those species. Group A is in light-blue, group B is in green, group C is in red, and group $\mathrm{D}$ is in yellow. Each point represents a sovereign country and all of its territories. Signatory states are indicated by squares, nonsignatory states are indicated by triangles, and countries that have signed at least one MoU but not CMS are indicated by circles. Select countries are labeled on the plot with three-letter country codes 
Table 1 Summary statistics of species richness and mean range-size of countries by group

\begin{tabular}{llllll}
\hline $\begin{array}{l}\text { Grouping } \\
\text { method }\end{array}$ & Group/region & $\begin{array}{l}\text { Number of } \\
\text { countries }\end{array}$ & $\begin{array}{l}\text { Mean number of CMS } \\
\text { species }\end{array}$ & $\begin{array}{l}\text { Mean range-size of species } \\
\text { (number of countries) }\end{array}$ & $\begin{array}{l}\text { Number of signatory } \\
\text { countries }\end{array}$ \\
\hline $\begin{array}{l}k \text {-means } \\
\text { clustering }\end{array}$ & A & 32 & 300.7 & 66.7 & $22(68.7 \%)$ \\
& B & 83 & 201.9 & 80.4 & $66(79.5 \%)$ \\
& C & 34 & 148.9 & 52.3 & $15(44.1 \%)$ \\
Geographic & North America & 46 & 74.0 & 86.5 & $18(39.1 \%)$ \\
region & Europe & 3 & 223.0 & 53.5 & $0(0 \%)$ \\
& Asia & 38 & 231.1 & 80.4 & $41(85.4 \%)$ \\
& Australia and Oceania & 19 & 227.4 & 71.3 & $16(41.0 \%)$ \\
& Africa & 54 & 66.2 & 82.2 & $7(36.8 \%)$ \\
& South America and the & 32 & 177.2 & 80.0 & $44(81.5 \%)$ \\
& Caribbean & & 114.8 & 32.0 & $13(40.6 \%)$ \\
\end{tabular}

Many countries in group $\mathrm{C}(65.9 \%)$ are not CMS parties (notably Indonesia, Canada, and Mexico). However, because species in this group tend toward smaller rangesizes, relevant countries may be more inclined to focus on smaller, local conservation initiatives rather than on a larger multilateral agreement like CMS. From a conservation perspective, each country in group $\mathrm{C}$ represents a large portion of the distribution of CMS species in that region such that species in this group depend on more constrained areas. Each nonsignatory country in group $\mathrm{C}$ may significantly limit the effectiveness of the convention as a conservation tool for this group.

The 46 countries clustered in group D have the smallest average number of CMS species-approximately one quarter of the species found in group A (Table 1). Composed predominantly of island states alongside a few African and very small European states, each of the countries in group D contain $<15 \%$ of CMS species which are shared with $35-55 \%$ of other United Nations member countries. Countries in this group that are not already signatories may be difficult to recruit to CMS as, not only are there few CMS species in these countries, but the species in group D countries also tend to be fairly cosmopolitan, which reduces the impact of a single state's participation. Many countries in this group are geographically restricted in size and in immediate proximity of other small states. It is also important to note that species occurring in many countries may still occur in relatively small land area depending on the geographic region in question.

When looking at the range-diversity diagram with a geographic (as opposed to species-based) perspective, new patterns emerge (Fig. 2). Europe, Asia, and North America contain large numbers of CMS species, while South America and the Caribbean, and Australia and Oceania contain relatively fewer listed species (Table 1). Each geographic region forms visually identifiable clusters on the range-diversity diagram. Notable exceptions to this include Caribbean countries and very small European states (e.g., San Marino). Unsurprisingly, these countries have similar properties to small Oceanic states than large mainland states. Range-diversity diagrams grouped by geography alone may over-generalize countries that are in close proximity but have dissimilar species patterns.

For the 2018-2020 budgetary period, 15 states will pay the minimum contribution (less than $€ 60$ year $^{-1}$ ), while the top four of the contributors (Germany, France, the United Kingdom, and Italy) will each pay more than $€ 200000$ year $^{-1}$ (UNEP/CMS Res 12.2, pp. 5-8; Table 2). The per-species cost to becoming a signatory is at least $14 \%$ higher for the richest nonsignatory states (the Unites States and Japan) than any current signatory state (Fig. 3, Tables 2, 3). The remaining largest nonsignatory states, China and Russia, have comparable per-species costs to the largest signatory countries. Among nonsignatory states, Myanmar, Thailand, Nepal, Vietnam, and Turkey stand out in particular (Fig. 3, Table 2) as countries containing a large proportion of CMS species $(>25 \%)$ and with relatively low participation costs $\left(<€ 250\right.$ species $^{-1}$ year $\left.^{-1}\right)$.

\section{CONCLUSIONS}

While most countries in Europe, Africa, and South America are members of CMS, there are gaps in participation across Asia and North America. Countries containing a large number of CMS species, particularly those with low participation costs such as Myanmar, Thailand, Nepal, Vietnam, and Turkey may be most amenable to joining CMS. In contrast, cost may be a deterrent for nonsignatory states with large economies, particularly for those countries containing few CMS species. Regardless, CMS must not 


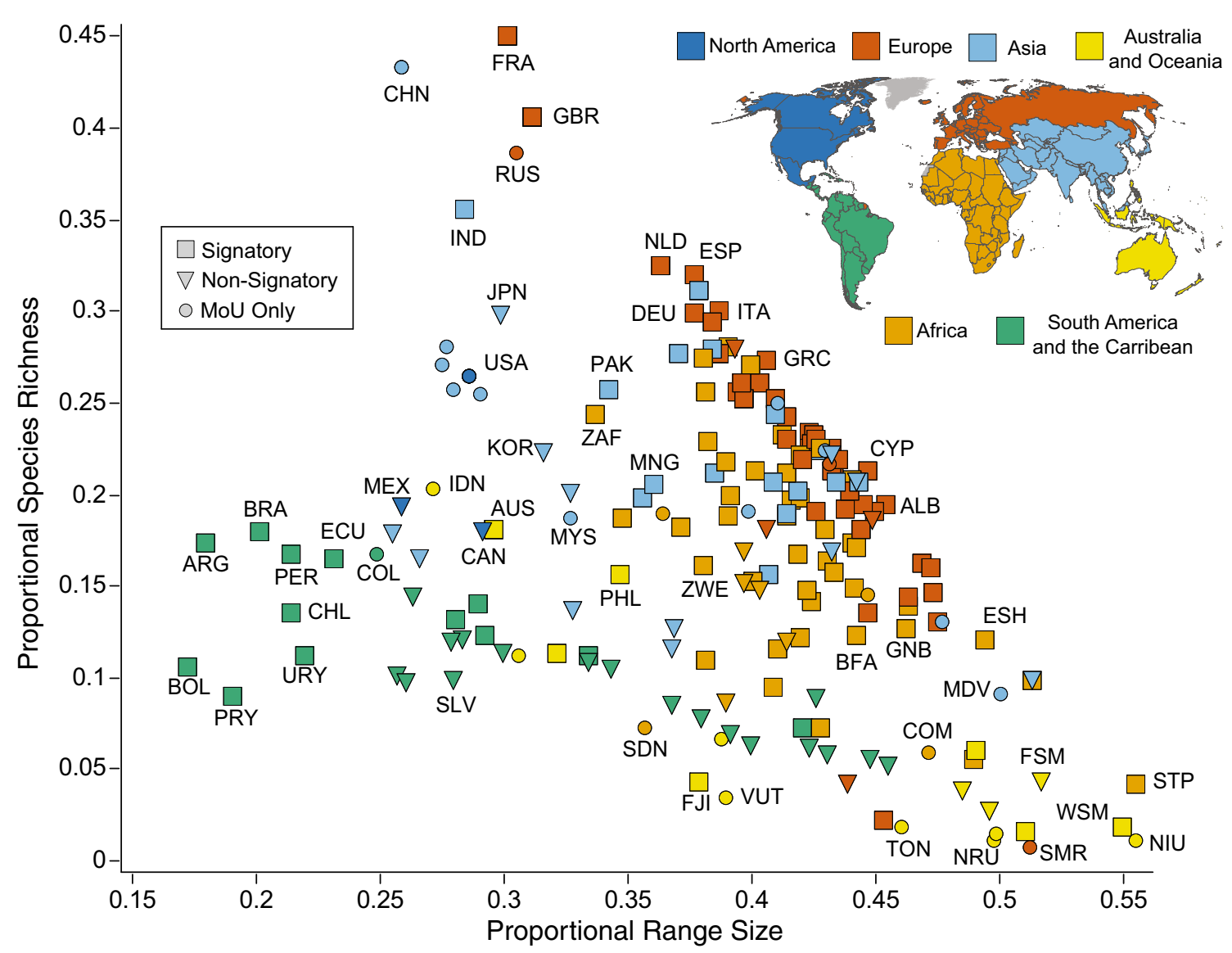

Fig. 2 Richness-diversity diagram of countries grouped by CMS geographic regions. Diagram depicts the relationship between the number of CMS species in a country and the average range-size of those species. North America is in dark-blue, Europe is in red, Asia is in light-blue, Australia and Oceania are in yellow, Africa is in orange, South America and the Caribbean are in green. Each point represents a sovereign country and all of its territories. Signatory states are indicated by squares, nonsignatory states are indicated by triangles, and countries that have signed at least one MoU but not CMS are indicated by circles. Select countries are labeled on the plot with three-letter country codes

Table 2 Expectation of financial contribution to CMS from nonsignatory states containing at least $25 \%$ of CMS species to become signatories based on proportional economic size (UNGA Res 70/416/Add.1, UNEP/CMS Res 12.2). Adjusted scale includes all signatory states

\begin{tabular}{lllrrr}
\hline Country & $\begin{array}{l}\text { CMS } \\
\text { species }\end{array}$ & $\begin{array}{l}\text { UN } \\
\text { contribution } \\
\text { scale }(\%)\end{array}$ & $\begin{array}{l}\text { Adjusted } \\
\text { scale }(\%)\end{array}$ & $\begin{array}{l}\text { Signatory } \\
\text { cost }(€)\end{array}$ & $\begin{array}{l}\text { Cost per } \\
\text { species } \\
(€)\end{array}$ \\
\hline China & 454 & 7.92 & 14.25 & 364907 & 803.76 \\
Russia & 406 & 3.09 & 6.10 & 156192 & 384.71 \\
Japan & 314 & 9.68 & 16.87 & 431918 & 1375.54 \\
Myanmar & 294 & 0.01 & 0.02 & 539 & 1.83 \\
Turkey & 294 & 1.02 & 2.10 & 53745 & 182.81 \\
Thailand & 284 & 0.29 & 0.61 & 15603 & 54.94 \\
USA & 277 & 22.00 & 31.42 & 804453 & 2904.17 \\
Vietnam & 270 & 0.06 & 0.12 & 3126 & 11.58 \\
Nepal & 267 & $<0.01$ & 0.01 & 324 & 1.21 \\
\hline
\end{tabular}

ignore the importance of pursuing geographically large nonsignatory countries that contain many species under the convention (e.g., Russia, China, Japan, and the United States). Of these countries, Russia and China would contribute comparable per-species cost to current signatory states with similar species compositions (e.g., France and the United Kingdom). The United States and Japan may be discouraged by disproportionately large costs necessary to become signatories. This cost burden may be alleviated with the addition of migratory species into CMS appendices with ranges in these countries.

For this study, the identity of individual species was not considered. However, it should not be assumed that all CMS species present equivalent conservation problems. CMS includes mammals, birds, retiles, fish, and one insect with diverse ecologies, modes of movement, and migratory habits in both terrestrial and aquatic environments. Species counts are useful for broad summaries, but it is unlikely that all species are valued equally by range-states. 


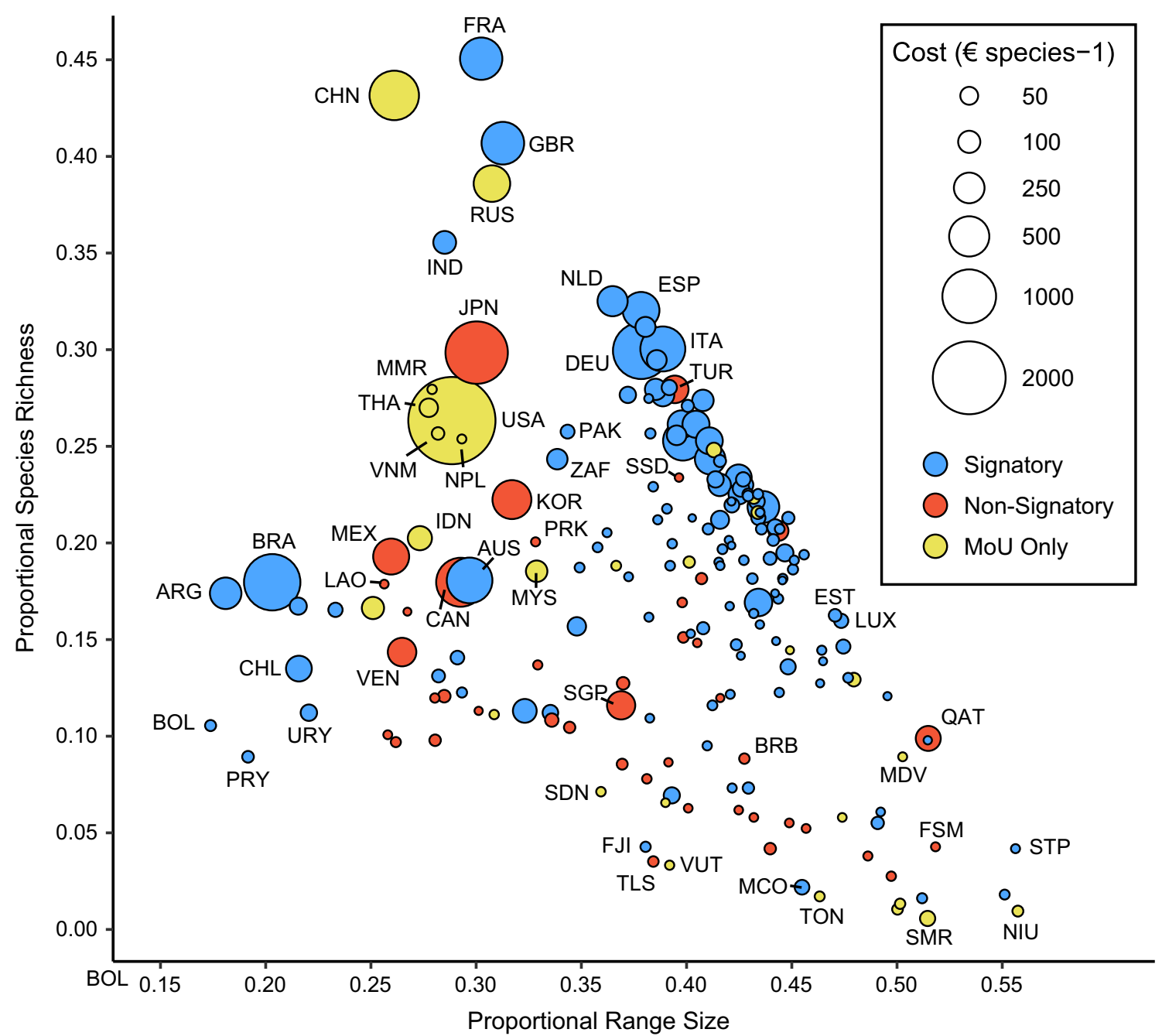

Fig. 3 Richness-diversity diagram depicting the relationship between the number of CMS species in a country and the average range-size of those species. Each point represents a sovereign country and all of its territories. The size of each point shows the per-species cost to be a CMS party state. Signatory states are blue, nonsignatory states are indicated by red, and countries that have signed at least one MoU but not CMS are indicated by yellow. Select countries are labeled on the plot with three-letter country codes

The only insect listed under CMS, the monarch butterfly, is a prime example of the difficulties the convention faces with conservation of migratory species across nonsignatory states. Monarch butterflies exhibit a wide geographic range including North America, Central and South Americas, Oceania, and Australia, Europe, and Africa, but only North American populations of monarch butterflies are migratory (Zhan et al. 2014). Canada, the United States, and Mexico are not parties to CMS, preferring instead to maintain independent initiatives (Oberhauser et al. 2008). While it is possible for CMS to facilitate conservation efforts of the monarch butterfly as a species, the convention has limited ability to conserve populations of monarch exhibiting migratory behavior with no North American signatory states.

Limitations in species distribution data restrict the efficacy of any conservation assessment (Seelarbokus 2014).
Distributions of migratory species are particularly difficult to catalog given their complicated and seasonal life histories (Riede 2004). The coarseness of available range data limited this study to a country-scale evaluation addressing only species included within CMS appendices. Future assessments of species composition patterns would benefit greatly from measures of geographic range and seasonality of movements.

The primary goal of the CMS secretariat is to facilitate cooperation and communication between member states in conservation efforts of migratory species that travel across international borders. CMS does not place stringent legal requirements upon its signatories unlike other MEAs such as CITES or CBD. Rather, CMS encourages the creation of smaller agreements that may themselves contain strict requirements. This approach appeals to states that opposed broad restrictions, but may hinder the efficacy of 
Table 3 Estimation of financial contribution to CMS from the 10 signatory states containing the largest number of CMS species based on proportional economic size (UNGA Res 70/416/Add.1, UNEP/ CMS Res 12.2). Adjusted scale includes only signatory states

\begin{tabular}{lllrrr}
\hline Country & $\begin{array}{l}\text { CMS } \\
\text { species }\end{array}$ & $\begin{array}{l}\text { UN } \\
\text { contribution } \\
\text { scale }(\%)\end{array}$ & $\begin{array}{l}\text { Adjusted } \\
\text { scale }(\%)\end{array}$ & $\begin{array}{l}\text { Signatory } \\
\text { cost }(€)\end{array}$ & $\begin{array}{l}\text { Cost per } \\
\text { species } \\
(€)\end{array}$ \\
\hline France & 474 & 4.86 & 10.24 & 262177 & 553.12 \\
UK & 428 & 4.46 & 9.41 & 240810 & 562.64 \\
India & 374 & 0.74 & 1.55 & 39766 & 106.33 \\
Netherlands & 342 & 1.48 & 3.12 & 79964 & 233.81 \\
Spain & 337 & 2.44 & 5.15 & 131817 & 391.15 \\
Israel & 328 & 0.43 & 0.91 & 23202 & 70.74 \\
Italy & 316 & 3.75 & 7.90 & 202231 & 639.97 \\
Germany & 315 & 6.39 & 13.47 & 344732 & 1094.39 \\
Portugal & 310 & 0.39 & 0.83 & 21151 & 68.23 \\
Egypt & 295 & 0.15 & 0.32 & 8201 & 27.80 \\
\hline
\end{tabular}

implementing localized conservation plans and protections (Baldwin 2011). CMS must focus on filling geographic gaps in participation for the agreement to be relevant on the international scale. Large geographic gaps in participation discourage nonsignatory states in North America and Asia from entering CMS on an individual basis. Nonsignatory countries may contain ecological regions critical to the conservation of a migratory species such as breeding sites, migratory flyways, stopovers, or wintering areas. Moreover, as global climate change influences migration patterns (Robinson et al. 2009), CMS may become increasingly important as an MEA. Without adequate participation from the global community, CMS is ultimately limited in its ability to facilitate conservation of migratory species.

Acknowledgements We thank the CMS secretariat for providing data and guidance for this study. We thank our funding sources: the National Science Foundation C-CHANGE Integrative Graduate Education and Research Traineeship [Grant Number 0801522], the Ecology and Evolutionary Biology Department of the University of Kansas, and the Biodiversity Institute Panorama Grant. We also thank Dr. Town A. Peterson and Kathryn Ingenloff for editing the manuscript.

Open Access This article is distributed under the terms of the Creative Commons Attribution 4.0 International License (http:// creativecommons.org/licenses/by/4.0/), which permits unrestricted use, distribution, and reproduction in any medium, provided you give appropriate credit to the original author(s) and the source, provide a link to the Creative Commons license, and indicate if changes were made.

\section{REFERENCES}

Arita, H.T., J.A. Christen, P. Rodríguez, and J. Soberón. 2008. Species diversity and distribution in presence-absence matrices: Mathematical relationships and biological implications. The American Naturalist 172: 519-532.
Baldwin, E.A. 2011. Twenty-five years under the Convention on Migratory Species: Migration conservation lessons from Europe. Environmental Law 41: 535-571.

Birnie, P.B., A. Boyle, and C. Redgwell. 2009. International law and the environment. Oxford: Oxford University Press.

Clobert, J., M. Baguette, T.G. Benton, and J.M. Bullock. 2012. Dispersal ecology and evolution. Oxford: Oxford University Press.

Dodds, F., M. Howell, M. Strauss, M.O. Onestini, E. Maruma, and A. Bourdy. 2007. Negotiating and Implementing Multilateral Environmental Agreements (MEAs): A manual for NGOs. Nairobi, Kenya: UNEP Division of Environmental Law and Conventions (DELC).

Esri. 2011. ArcGIS Desktop. 10 ed. Redlands, CA: Environmental Systems Research Institute.

Graves, G.R., and C. Rahbek. 2005. Source pool geometry and the assembly of continental avifaunas. Proceedings of the National Academy of Sciences 102: 7871-7876.

Guruswamy, L.D. 1999. The convention on biological diversity: Exposing the flawed foundations. Environmental Conservation 26: 79-82.

Guruswamy, L.D., and K.L. Doran. 2007. International environmental law. St. Paul, MN: Thomson/West.

Kim, R.E. 2013. The emergent network structure of the multilateral environmental agreement system. Global Environmental Change 23: 980-991.

Koester, V. 2002. The five global biodiversity-related conventions: A stocktaking. Review of European, Comparative \& International Environmental Law 11: 96-103.

Macqueen, J. 1967. Some methods for classification and analysis of multivariate observations. Proceedings of the fifth Berkeley symposium on mathematical statistics and probability. 1: 281-297. Oakland, CA.

Oberhauser, K., D. Cotter, D. Davis, R. Decarie, A. Behnumea, C. Galino-Leal, M. Gallina Tessaro, E. Howard, et al. 2008. North American monarch conservation plan. Montreal: Commission for Environmental Cooperation.

R Core Team. 2017. R: A language an environments for statistical computing. 3.3.3 ed. Vienna: R Foundation for Statistical Computing.

Riede, K. 2004. Global register of migratory species: From global to regional scales: Final report of the R\&D-Projekt 80805081. Federal Agency for Nature Conservation.

Robinson, R.A., H.Q. Crick, J.A. Learmonth, I. Maclean, C.D. Thomas, F. Bairlein, M.C. Forchhammer, C.M. Francis, et al. 2009. Travelling through a warming world: Climate change and migratory species. Endangered Species Research 7: 87-99.

Seelarbokus, C.B. 2014. Assessing the effectiveness of International Environmental Agreements (IEAs). SAGE Open 4: 2158244014521820. https://doi.org/10.1177/2158244014521 820.

Soberón, J., and J. Cavner. 2015. Indices of biodiversity pattern based on presence-absence matrices: A GIS implementation. Biodiversity Informatics. https://doi.org/10.17161/bi.v10i0.4801.

Soberón, J., and G. Ceballos. 2011. Species richness and range size of the terrestrial mammals of the world: Biological signal within mathematical constraints. PLOS ONE 6: e19359.

United Nations Environment Programme/Convention on the Conservation of Migratory Species, 23-28 October 2017. Resolution 12.2 .

United Nations General Assembly, 23 December 2015. Resolution A/RES/70/416/Add.1.

Zhan, S., W. Zhang, K. Niitepold, J. Hsu, J.F. Haeger, M.P. Zalucki, S. Altizer, J.C. De Roode, et al. 2014. The genetics of monarch butterfly migration and warning colouration. Nature 514: 317-321. 


\section{AUTHOR BIOGRAPHIES}

Christopher Michael Hensz $(\square)$ is a doctoral candidate at the University of Kansas. His research interests include movement ecology of migratory species and biodiversity policy.

Address: Department of Ecology and Evolutionary Biology and Biodiversity Institute, University of Kansas, 1345 Jayhawk Blvd, Lawrence, KS 66045, USA.

e-mail: hensz@ku.com
Jorge Soberón is a distinguished professor at the University of Kansas. His research interests include documenting and understanding large-scale spatial patterns in the biodiversity of terrestrial species.

Address: Department of Ecology and Evolutionary Biology and Biodiversity Institute, University of Kansas, 1345 Jayhawk Blvd, Lawrence, KS 66045, USA.

e-mail: jsoberon@ku.edu 